\title{
SUAREZ E A DOUTRINA DAS FORMAS SUBSTANCIAIS
}

André Rangel Rios*

SÍNTESE - As Disputationes Metaphysicae de Suárez constituem a maior tentativa de expor sistematicamente a Metafísica. Suárez, por problemas teológicos, admite uma separação entre a substância material e 0 acidente de quantidade. Para tanto, analisa a fundo as noções de matéria primeira e de forma substancial.

\begin{abstract}
The Disputationes Metaphysicae elaborated by Francis Suárez are the greatest attempt to explain the Metaphysics. On account of theological problems, this philosopher admits the separation of the material substance and the accident of quantity. Therefore he works out a deep analysis of two notions, namely materia prima and forma substantialis.
\end{abstract}

As Disputationes Metaphysicae (1597) [DM] seria a primeira obra de grande envergadura da tradição filosófica a buscar expor de um modo completo a metafísica segundo a ordo doctrinae [DM ad lectorem]. Haveria nas DM uma ordenação coerente e fundamentada dos temas que constituem as disputationes. As disputationes são por sua vez subdivididas em sectiones. Há intérpretes que vêem na sistematicidade das DM um avanço na direção da autonomização da metafísica frente à teologia.

Tratados versando somente sobre metafísica já existiam, contudo, desde muito. Mesmo os comentários sobre a Metafísica de Aristóteles sempre buscaram apresentar o seu pensamento de um modo mais ou menos ordenado; estes comentários purgavam as repetições e adiavam discussões prematuras vindo portanto a desenvolver-se segundo uma sistemática talvez não tão menos satisfatória que as das DM. Além disso, distinguir a discussão filosófica da teológica não pode ser visto no séc. XVI como uma novidade para a escolástica.

\footnotetext{
- Universidade Estadual do Rio de Janeiro.
}

1 Este texto não foi escrito inicialmente com a intenção de ser publicado. Ele deveria apenas servir como um apoio para a exposição oral que realizei na USP em novembro de 1992 por ocasião de um colóquio sobre as formas substanciais. Devido à inexistência quase absoluta de publicações sobre Suárez no Brasil acabei, porém, por decidir publicá-lo como artigo. Estando, entretanto, ocupado em diversas outras pesquisas não me permiti mais do que rever superficialmente a pontuação e escrever de um modo mais completo as referências bibliográficas que já haviam sido deixadas indicadas no manuscrito. Há, porém, no texto inúmeras referências bibliográficas indiretas que não pude acrescentar por extenso.

\begin{tabular}{|l|l|l|l|l|l|}
\hline VERITAS & Porto Alegre & v. 41 & $\mathrm{n}^{0} 163$ & Setembro 1996 & p. $525-539$ \\
\hline
\end{tabular}


A relevância das DM está talvez na incorporação da discussão metodológica do séc. XVI e na extensão e qualidade de sua discussão dos temas fundamentais do aristotelismo escolástico.

No entanto, se poderia dizer ainda que as DM são uma aparatosa demonstração de poder, uma auto-afirmação da escolástica jesuitica e, assim, da escolaridade católico-eclesial.

A trama discursiva dos séc. XVI/XVII é, como nós bem sabemos, complexa. Porém é certo que as DM não representam então o canto dos cisnes da escolástica que, com o cartesianismo, teria tido de conformar-se com uma aposentadoria compulsória. O aristotelismo escolástico fez ainda muita história bem após as DM.

As DM se inserem na complexa urdidura dos atritos intrajesuíticos (Suárez vs. Vasquez), dos embates intracatólicos (Suárez vs. Bañez), da intolerância religiosa (católicos vs. protestantes), das animosidades políticas (colonização, cristianização e jus gentium; Belarmini vs. Jaime I) e dos confrontos epistemológicos (Aristotelismo vs. atomismo; vitalismo vs. mecanicismo). Com as DM está Suárez atirando em várias direções ou, ao menos, apoiando e consolidando a base de seus argumentos em outras polêmicas, a saber, em polêmicas teológicas e político-eclesiásticas. Há que se notar também que seu latim correto, seu discreto cultivo das bonae litterae, vale tanto como uma crítica à escolástica medieval quanto como uma apropriação do prestígio do Resnascimento.

Considerando-se, no entanto, de um modo mais amplo o multifacético movimento intelectual europeu (e colonial: pois já há então universidades no Novo Mundo) talvez se deva dizer que as DM não são uma obra das mais inovadoras. As DM não reforçam a divisão entre metaphysica generalis e metaphysica specialis. Nelas a separação entre filosofia e teologia é, na verdade, por vezes não observada: tanto Suárez discute longamente temas teológicos (como a transubstanciação) como chega a remeter para tratados de teologia temas que ele próprio diz serem filosóficos (p. ex., a questão da scientia conditionata). Ao contrário de escotistas como Mastrius ele inclui a doutrina das causas na metafísica. Além disso, Suárez não se submete de modo rigoroso à sempre tão louvada sistematicidade de sua obra, isto é, à ordo doctrinae.

Nas DM a ordem das disputações é a seguinte:

Disp. 1: $\quad$ A natureza da filosofia primeira (pode ser vista como uma introdução geral às DM)

Disp. 2: $\quad$ O objeto da metafísica (trata-se aqui, pois, de se estabelecer o fundamental da metafísica)

Disp. 3-11: passiones entis

Disp. 12-27: as causas

Disp. 28: $\quad$ a divisão entre ens finitum e infinitum

Disp. 29-30: Deus

Disp. 31-53: sobre o ente finito

Disp. 31:

Disp. 32:

Disp. 33-36: sobre $o$ ente finito em geral

Disp. 37-53: sobre os acidentes

Disp. 54:

sobre os entia rationis 
Esta sistematicidade está porém rompida em vários momentos. As rupturas mais evidentes são, a meu ver, as seguintes: (1) A inclusão da disputação 7 sobre as distinções no meio da série das disputationes sobre as passiones entis. (2) A inclusão de uma extensa discussão sobre a verdade das proposições ou do conhecimento na disputação 8 que deveria versar apenas sobre a verdađe transcendental. (3) A inclusão, ao final das DM, da disputação 54 sobre os entia rationis os quais Suárez reconhece explicitamente como não pertencentes ao objeto da metafísica.

Contudo, sabe-se que as DM foram basicamente bem divulgadas na Europa, inclusive entre os protestantes. Após um primeiro momento - luterano - de hostilidade à escolástica, a escolástica - com apoio de Melanchton - acabou por entrar nas universidades protestantes. Por esta via é que as DM acabaram por ser lidas na Alemanha dos séculos XVII e XVIII. Porém aqui há que se chamar também atenção para um outro fato. Suárez é muito pouco citado por autores tidos por significativos tais como Descartes, Malebranche ou Leibniz. Apenas Wolff o cita com freqüência. Influências palpáveis de Suárez são, ao final, difíceis de serem delimitadas. Suárez parece ter sido lido fora da escolaridade escolástica católica basicamente como um manual, completo e mesmo criativo, isto é, parece ter sido lido sempre em partes, quase como se as disputações independessem umas das outras. Os jesuítas à parte, não se pode falar, no séc. XVII, de um suarezianismo tal como se fala de um cartesianismo.

Porém Suárez é, sem dúvida, uma presença no final do séc. XVI e XVII. É certo que é difícil determinar qual tenha sido o seu papel na história do pensamento filosófico. Contudo também não é claro em que sentido a filosofia é histórica ou mesmo o que seja filosofia. Em todo o caso os que valorizam a importância de Suárez parecem por vezes ter algum interesse nisso: ou querem afirmar uma certa continuidade entre a escolástica e a modernidáde e, ao mesmo tempo, uma certa dependência da modernidade em relação à escolástica, ou querem simplesmente afirmar a escolástica e sugerir que ela detém uma certa perenidade (ultimamente, porém, isto só tem acontecido raramente). Mas há também aqueles que apenas estariam buscando ver as vicissitudes dos séculos XVI e XVII de um modo mais nuanceado, embora aqui também sempre se possa supor que estes pesquisadores estejam sendo movidos por alguma interpretação do que seja a modernidade e, conseqüentemente, de como tenha sido o seu surgimento e constituição. Pode-se mesmo dizer que qual relevância se vem a atribuir a Suárez e às suas DM depende sempre de como se está interpretando ou tendendo a valorizar a modernidade. ${ }^{2}$

Antes de comentar a teoria suareziana das formas substanciais gostaria ainda de retornar à questão das rupturas na sistematicidade das DM. Se abstrairmos as interrupções para digressões teológicas podemos dizer que as principais rupturas de ordem filosófica são: (1) a doutrina das distinções, (2) a verdade do conhecimento e (3) os entia rationis.

O que quero destacar é que a sistematicidade das DM não dá conta de subsumir principalmente três doutrinas 'marginais' que são, no entanto, fundamentais

2 Poder-se-ia discutir aqui por que e em que medida Heidegger no Sein und Zeit $\S 6$ e nos Grundprobleme der Phänomenologie § 10 se refere com certa reverência a Suárez. Qual o "interesse" de Hejdegger em relação à escolástica? 
para a compreensão da maioria das disputações: (i) a doutrina das distinções (e conseqüentemente a dos modi: ${ }^{3}$ os modi reales dizem respeito a distinctio modalis), (ii) a doutrina da denominatio extrinseca e (iii) a doutrina dos entia rationis. Cabe aqui indicar que destas a mais 'rebelde' é a doutrina da denominatio extrinseca e que as duas outras doutrinas não são compreensiveis sem uma referência fundamental à doutrina da denominatio extrinseca.

Em todo o caso, enquanto Suárez dedica algumas passagens à doutrina dos modi intrinseci e uma disputação inteira aos entia rationis, a doutrina da denominatio extrinseca pemanece em sua obra obscura, não discutida e não sistematizada. Ela porém é que reincidentemente ameaça a sistematicidade das DM.

A impossibilidade de que tratemos aqui a questão da denominação extrínseca, questão que, aliás, já tratei de um modo mais extenso, embora não de todo satisfatório, em um outro texto, me leva a contentar-me apenas com estas indicações e de concluir dizendo que dois são os motivos básicos para as repetidas rupturas na sistematicidade das DM: (a) problemas internos ao próprio discurso metafísico que vêm se manifestar principalmente na 'rebeldia' das denominationes extrinsecae e (b) a não-separação clara por Suárez entre filosofia e teologia (comentando abaixo o texto da disputação sobre a quantidade veremos que Suárez lança mão com a mesma naturalidade tanto de argumentos de caráter teológico quanto de argumentos propriamente filosóficos).

Mas detenhamo-nos ainda um pouco exatamente no momento em que a sistemática das DM é rompida pela primeira vez de um modo mais relevante, a saber, detenhamo-nos na disputação 7 sobre os vários gêneros de distinções.

Suárez aceita as seguintes distinções:

1) A distinctio realis: é a que ocorre entre duas coisas (rei a re - DM $7,1,1$ ) reciprocamente independentes e assim realmente distintas uma da outra.

2) A distinctio rationis: é a que não pré-existe nas coisas (non est in rebus - DM $7,1,1)$ antes da atividade do intelecto. Há dois tipos de distinção de razão:

2.1) a distinctio rationis ratiocinantis que se deve de fato apenas à atividade do intelecto: seria pois uma distinção feita pela razão enquanto ela raciocina por ela própria.

2.1) a distinctio rationis ratiocinata que embora se deva também à atividade do intelecto ela também se deve a uma 'ocasião' dada pela coisa: seria pois uma distinção feita pela razão enquanto ela é levada a raciocinar de uma determinada maneira.

3) A distinctio modalis: é uma distinção atual, ex natura rei e anterior à atividade do intelecto, mas que não é tanta quanto a distinção entre duas coisas. Trata-se aqui da distinção entre a coisa e o seu modo. Temos portanto que, a seguir, considerar brevemente a teoria suareziana dos modos. ${ }^{4}$

3 A teoria suareziana dos modi, isto é, dos modi intrinseci ou modi reales, não deve ser relacionada à doutrina escotista dos modi intrinseci. A doutrina de Suárez é um desenvolvimento de uma teoria dos modi que Fonseca em parte propõe [Cf. DM 7,1,19] e que parece remeter, em última instância a Durandus a Sancto Porciano.

4 A principal publicação sobre o tema, apesar de suas muitas limitações, é a de Alcorta. 
Antes porém de expormos a doutrina dos modi convém notar que as distinctiones rationis são entia rationis, ou seja, 'elas resultam de atos reflexos do intelecto, no caso, reflexos sobre denominationes extrinsecae. Suárez não define em nenhum lugar de suas obras o que seja a denominatio extrinseca. Nem por isso o conceito de denominatio extrinseca pode deixar de ser considerado como um conceito básico para ele. Já na disputação 2 sobre o conceito objetivo de ser, isto é, sobre o objeto da metafísica a denominatio extrinseca se mostra um conceito fundamental. É ao esclarecer o que seja o conceptus objectivus que Suárez deixa a denominatio extrinseca entrar em cena: "[...] conceptus objectivus, conceptus quidem per denominationem extrinsecam a conceptu formali [...]" [DM 2,1,1].

$\mathrm{O}$ que temos é que o conceito objetivo é uma denominação extrínseca. Mas em que sentido propriamente? Em Suárez a denominação extrínseca é tanto o referir quanto o ser referido, ou seja, é tanto o ver quanto o ser visto, tanto o denotar quanto o ser denotado. Suárez deixa esta expressão valer, ora em um sentido ativo, ora em um sentido passivo. É exatamente nesta oscilação que ela funciona, que ela percorre todas as DM e mesmo que possibilita muitas articulações essenciais a esta obra. A própria doutrina da denominação extrínseca permanece porém não sistematizada, não tematizada e portanto não discutida. As razões disto não cabe porém discutir aqui. Retornemos, assim, à apresentação da doutrina suareziana dos modos.

Para Suárez há modos substanciais e modos acidentais. Os modos substanciais são três:

- modus unionis que une a materia e a forma substancialis.

- modus subsistentiae que é a substantia prima que se une intrinsecamente com a essentia ou natura.

- modus dependentiae que é próprio a toda substância criada que enquanto tal depende da criação divina.

Os modos acidentais são vários e, sem buscar ser exaustivo, vou enumerá-los ao indicar resumidamente como Suárez entende os acidentes:

2. quantitas: realmente distinto da substância $=$ modus inhaerentiae

3. qualitas:

3.1. habitus e dispositio $\rightarrow$ modus in ordine ad naturam subjecti

3.2. potentia e impotentia $\rightarrow$ modus secundum actionem et passionem

3.3. passiva qualitas $\rightarrow$ modus secundum actionem et passionem

3.4. figura $\rightarrow$ modus secundum quantitatem ${ }^{5}$

4. relatio: distinctio rationis da realidade do fundamento (resultantia naturalis)

5. actio: distinctio rationis ratiocinata [DM 49,1,8] do termo da ação que é o modus intrinsecus da passio

6. passio: modus intrinsecus de dependência da ação

7. quando: distinctio rationis da existência do fundamento

8. ubi: modus intrinsecus (resultantia naturalis)

9. situs: distinctio rationis do ubi

10. habitus: denominatio extrinseca ${ }^{6}$

5 Cf. DM 42,1,1 e DM 42,5,5.

6 Sobre a relatio e o habitus (enquanto décimo predicamento) cf. Rios. Sobre a resultantia naturalis cf. Elorduy e Rios. 
Para esclarecer o que Suárez entende como modus realis o mais prático é comentar os modi que dizem respeito ao nosso tema de hoje.

A matéria e a forma são cada uma uma substância incompleta. A matéria pode, para Suárez, inclusive subsistir sem a forma. Como se dá a união entre a matéria e a forma? O modus unionis é que as une, as une sem porém ser uma terceira coisa entre elas. Se fosse uma terceira coisa independente ter-se-ia ainda que explicar como a matéria e a forma se unem a esta terceira coisa. A união entre matéria e forma é assim algo de positivo que se acrescenta a ambos mas não seria algo de totalmente diferente.

A quantidade é um acidente que enquanto tal é realmente diferente da substância na qual ele inere. Não é porém a quantidade enquanto tal que inere na substância diretamente, mas isto ocorre por meio do modus inhaerentiae. A quantidade é assim um acidente com entidade própria que inclusive pode ser conservado se separado da substância, ou seja, a inerência não é essencial a ele, é algo que é acrescido a ele no ato da união ou inerência com a substância. Isto é particularmente importante para que se explique a transubstanciação, pois a substância pão é desintegrada vindo a substância corpo de Cristo ocupar o seu lugar; porém os acidentes do pão são mantidos e passam a inerir na substância corpo de Cristo.

A quantidade é assim um acidente com uma grande independência entitativa da substância. Os outros acidentes não possuem a mesma independência ontológica. Na verdade, Suárez dá aos acidentes bem mais, por assim dizer, densidade ontológica que outros filósofos da escolástica. Principalmente os seis últimos predicamentos sempre foram questionados a respeito do status ontológico que lhes caberia ou mesmo se eles chegavam a ser propriamente entes, isto é, se afinal não se poderia, de um ponto de vista ontológico, reduzir todos os predicamentos a apenas os da quantidade, da qualidade e da relação. Os textos mais conhecidos nesta linha de discussão foram: o pseudo-Agostinho Categoriae decem, o Liber de sex principiis de Gilbertus Porretanus e o Liber sex principiorum atribuído a Alberto Magno. Para Ockham ontologicamente positivo é apenas a qualidade: ele não considera a quantidade algo distinto da substância. Ao contrário, em Suárez ontologicamente "fraco" é o décimo acidente, o do habitus, que não é mais do que uma denominação extrínseca, isto é, ele não é propriamente algo de real. Além disso, para Suárez, a relatio e o quando distinguem-se apenas ratione do fundamento, isto é, são algo real mas não constituem enquanto tais nada que é acrescentado à coisa já existente.

É na disputação 40, sectio 2, que Suárez discute a sua posição de que a quantidade se distingue realmente da substância. Aqui ele contesta a posição dos nominalistas de que a quantidade não difere realmente da substância. É importante destacar que os dois principais argumentos de Suárez [DM 40,2,8 e DM 40,2,14] são explicitamente baseados na teologia dogmática, a saber, nos dogmas acerca da eucaristia.

Para Suárez, na transubstanciação os acidentes são mantidos independentes da substância pão. ${ }^{7}$ Deus pode, segundo Suárez, manter uma substância material

7 Não se trata propriamente de uma annihilatio da substância do pão (e portanto da matéria primeira que ele inclui), mas de uma desitio substantiae, digamos que se trata de uma "desintegração" da substância pão. 
existindo retirando-lhe o acidente da quantidade [DM 40,2,21] ou mesmo conservar a mesma substância em diversos ubi. O fulcro do argumento de Suárez contra os nominalistas está em que eles não chegam a "salvar o mistério" a não ser recorrendo a milagres contínuos ("mysterium tamen nullo modo salvari posset, nisi fingendo continua miracula" - DM 40,2,13). E se os nominalistas argumentam - tal nos relata cuidadosamente Suárez [DM 40,2,3] - que não se deve acrescentar distinções sem necessidade ("[...] quia rerum distinctio introducenda vel asserenda non est sine ratione aut necessitate cogente [...]"), Suárez de certo modo contrapõe que a sua própria posição exige menos milagres para explicar a eucaristia, ao menos ele pensa que a sua posição não precisa recorrer aos - pelo visto embaraçosos - "milagres contínuos". Economizar milagres divinos parece, portanto, tornar uma posição mais plausível do que economizar distinções ontológicas.

O que ocorre na eucaristia é, segundo Suárez, que a substância pão é transubstanciada em corpo de Cristo enquanto uma carapaça de acidentes, suportados pelos acidentes da quantidade, se mantêm intacta. Fica mantida a extensão do pão, a figura (qualidade da quarta espécie) como modus da quantidade, o ubi destes acidentes, bem como o quando e eventuais passiones.

Suárez visa com sua teoria da quantidade e da substância propor uma metafísica estritamente compatível com a dogmática católica, a saber, com uma dogmática cuja formulação fora aprimorada algumas décadas antes das DM pelo concílio de Trento, mas que, como se sabe, desde os seus primórdios constituiu-se baseada em uma terminologia forjada pela própria tradição greco-latina em seu processo de apropriação pelo cristianismo.

A dificuldade com a qual se defronta Descartes no que ele busca propor uma metafísica que venha a superar a escolástica é como dar conta dos dogmas do Catolicismo do qual ele é fiel devoto.

Descartes acaba por renunciar às formas substanciais no que ele, por assim dizer, "desobjetiviza" as qualidades e substancializa a quantidade. A questão que pode ser colocada é se o cartesianismo chegou a dar uma explicação que compatibilizasse a renúncia às formas substanciais com a transubstanciação. A crer pelo Dictionnaire de Théologie Catholique até o séc. XX a igreja católica nutriu desconfiança a respeito da possibilidade de uma doutrina cartesiana acerca da eucaristia.

Mas não é só o dogma da eucaristia que apoia a doutrina das formas substanciais. É toda uma série de conceitos que de um modo mais ou menos estreito se ligam a esta doutrina. Acabamos de abordar rapidamente a doutrina dos predicamentos. Mas a psicologia de então, o conceito de vida, o conceito de matéria, a compreensão dos fenômenos astronômicos ou mesmo o conceito de método científico estão de alguma maneira compatibilizados com o conceito de formas substanciais. Não que todos estes conceitos e doutrinas se harmonizem sem atritos, ao contrário, há problemas por toda a parte. Aliás, problemas sempre os houve e para eles nunca se deixou de constituir a devida disputatio. Muitos problemas permaneceram com soluções insatisfatórias. Contudo, a escolástica nem por isso esmoreceu ou, ao menos, conseguiu juntar forças e reafirmar-se no séc. XVI mantendo sua vitalidade por todo o séc. XVII. 
É na disputatio 15 que Suárez expõe a sua doutrina das formas substanciais. Ele não busca nesta disputação propor nenhuma inovação significativa dentro da tradição escolástica. Suárez define a forma substancial [DM 15,5,1] como a forma que unindo-se à matéria primeira constitui uma substância da qual ela é o elemento específico. Em suas palavras: "substantia simplex, incompleta, quae ut actus materiae cum ea constituit essentiam substantiae completae". Na verdade, pode-se dizer que sua exposição sobre as formas substanciais se inicia na disputação 13 sobre a matéria, isto é, sobre a causa material. A demonstração da existência da matéria é pressuposta logo no início da disputação sobre as formas substanciais. O conceito suareziano de matéria afasta-se do de Tomás de Aquino no que ele não aceita propriamente que a matéria seja uma potência pura (para ele a materia prima é uma potência pura somente em relação à possibilidade de receber as diversas "informações" das formas substanciais, mas não enquanto toda a sua atualidade viria da forma) e aproxima-se de Duns Scot no que aceita que Deus pode manter a matéria independentemente da forma, embora recuse a doutrina da forma corporeitatis que ele atribui também a Duns Scot. A forma corporeitatis seria a doutrina que postula que a matéria sempre está "informada", porém que haveria uma forma extremamente simples que seria a que ficaria informando a matéria quando se buscasse destituí-la de todas as formas substanciais mais complexas.

A primeira sectio da disputação sobre a matéria coloca a questão de se é evidente para a razão natural a existência da matéria primeira. A primeira evidência alegada por Suárez é que no que se constata a mudança nas coisas também se constataria a constância de um substrato [DM 13,1,4]. Isto seria experimentalmente constatável ("experimento constat"). Mas a evidência que ele considera principal é a que diz respeito às coisas que são geradas ou que perecem ("res generabiles et corruptibiles"), ou seja, os processos de geração de novas coisas e de mudança das coisas geradas que crescem e morrem são também evidências experimentais da substância primeira ("evidens experientia" DM 13,1,5). Ainda mais porque se evidencia que um mesmo substrato suporta, em momentos diferentes, contrários. Isto sugere portanto uma materia prima indiferentemente receptiva de formas diversas. A existência da matéria primeira é conquistada por um misto de observação e argumentação racional. Trata-se para Suárez, sem dúvida, de uma certeza "científica", mas de uma certeza de grau correspondente ao que pode ser conquistado pela física, no caso aqui pela metafísica no que ela considera o conceito de causa de um modo algo mais universal do que o faz o físico. Ou seja. Não se chega à conclusão da existência da matéria primeira senão por meio de uma negotiatio da razão. Suárez não usa aqui o termo negotiatio, mas é como negotiatio que Zabarella entende a exposição de Aristóteles sobre a matéria primeira que ele comenta da seguinte maneira:

"A matéria é portanto descoberta por meio da geração, embora de início não se saiba ainda que ela é causa da geração: pois ainda ignora-se o que seja a matéria: por isso Aristóteles, que quis ensinar-nos o conhecimento dos princípios não só de um modo confuso, mas também tão distintamente quanto é possivel para a filosofia da natureza, começou por ínvestigar as condiçōes próprias à matéria que ele havia descoberto... Ele ensinou-nos primeiramente 
como ela difere da privação: pois a função da matéria é suportar contrários e recebê-los: a função dos contrários é se repelirem desta matéria: assim a matéria permanece sob ambos os contrários e não perece... deve portanto a matéria segundo a sua natureza carecer de todas as formas e lhe ser possível tudo receber: esta é sem dúvida a natureza da matéria, nada ser em ato e tudo em potência [esta porém não é exatamente a posição de Suárez]". <J. Zabarella 1607a col. 488 De rebus naturalibus citado in Schmitt p. 692>

Na sectio 2 Suárez defenderá a unidade da materia prima e contestará a pluralidade da matéria proposta na teoria atomista de Leucipo e Demócrito. Contestará também que haja vários elementos materiais como propôs Empédocles. Para Suárez só há uma materia prima receptiva a todas as formas. Esta matéria primeira não é nenhuma substância íntegra mas uma substância incompleta, foi criada por Deus e não é corruptível, pois é somente uma substância composta que pode se corromper retornando a um estado anterior; p. ex., um ser vivo pode tornar-se um ser inanimado, mas a matéria primeira não tem a que estado retornar. A matéria não exclui portanto todo o ato podendo existir - sustentada por Deus - independentemente de uma forma substancial, mas tende intrinsecamente a receber formas substanciais de modo que normalmente está sempre composta com alguma forma substancial. ${ }^{8}$ Quanto ao conceito que podemos ter da matéria Suárez indica que tal conceito só pode ser obtido por analogia com a matéria das coisas artificiais. O conceito da matéria primeira só pode portanto para nós ser conhecido de um modo em parte negativo e confuso [DM 30,6,4]. Deus porém, que criou a matéria, tem em si a idéia da matéria [DM $13,6,1]^{9}$

Gostaria de destacar ainda desta discussão sobre a materia prima três coisas. $<1>$ Primeiramente que na discussão da materia prima Suárez por vezes parece pressupor que já aceita que há formas substanciais. De fato o conceito de matéria como potência a receber todas as formas pressupõe que há formas a serem recebidas. Por isso quando na disputatio 15 Suárez pressupõe a demonstração da matéria primeira, ele está argumentando de certo modo circularmente. Contudo, isto é aceitável pois não se trata aqui de uma argumentação dedutiva, mas de, como já indiquei, uma negotiatio que baseia-se na "experiência" ("experimento constat") e que vem a ser confirmada exatamente na medida em que houver uma compatibilidade entre as diversas doutrinas correlatas, no caso entre o conceito de matéria e o de forma substancial. <2> Além disso é interessante indicar que a preocupação de Suárez em refutar o atomismo não parece ser mera retórica acadêmica, embora também não deixe que transpareça um empenho particularmente grande. Contudo é conveniente lembrar que as doutrinas atomistas que pressupõem o espaço vazio (o vácuo) são também de certo modo refutadas na disputação sobre o ubi na qual Suárez argumenta contra a possibilidade da existência de espaços vazios no mundo. $<3>$ Por fim cabe assinalar que o tema dos minima naturalia que Alberto Magno sugere no séc. XIII que Buridan retoma no séc. XIV argumentando que uma substância abaixo do seu minimum naturale se torna instável e que volta a ser tema de discussão no séc. XVI sendo então discutido e aceito até por Francisco

8 Suárez evidentemente não aceita a doutrina da individualização pela matéria. Para ele o princípio de individuação se distingue ratione da entidade que ele individualiza.

9 Há ainda vários aspectos da discussão sobre a matéria que - por razão da necessária brevidade estou deixando inteiramente de lado, tal como a questão da matéria dos corpos celestiais. 
Toleto (tio de Suárez) não é comentado pelo próprio Suárez. No séc. XVII Sennert buscará conciliar esta teoria aristotélica dos minima com o atomismo de Demócrito. Ou seja, nem tudo que é da escolástica está contido nas enciclopédicas DM.

Na sectio 1 da disputação 15 Suárez busca demonstrar a existência da forma substancial. Para isto ele inicia sua argumentação se referindo à substância racional, isto é, ao homem. A alma racional, diz Suárez, é substância e não acidente tanto que ela pode ser separada do corpo e permanecer por si só uma vez que é imortal $[15,1,6]$. Ao contrário da sectio 1 da disputação 13 sobre a existência da matéria primeira aqui Suárez já de início chega a um tema teológico, a saber, a imortalidade da alma. É certo que também há filósofos que concluíram - supostamente apenas baseados na razão natural - a alma ser imortal, tal como Platão. Contudo, com o advento do cristianismo o tema da imortalidade da alma não mais deixará de ter um incontestável compromentimento teológico. É Suárez mesmo quem cuida de lembrá-lo ("ut docet fides"), ainda que ele afirme também o caráter racional de tal crença ("et est etiam evidens lumine naturali"). A alma racional é de tal modo intrínseca ao corpo que o vivifica, além do que é através dela que o homem entende e raciocina, de modo que se a alma fosse extrínseca ao corpo seria como se um outro raciocinasse e não o próprio homem. Esta forma substancial racional é o pressuposto para a geração e nutrição do homem permanecendo ainda após a sua morte $[15,1,7]$.

O segundo argumento de Suárez para demonstrar as formas substanciais baseia-se em vários indícios observados nos acidentes e na atividade dos entes naturais $[15,1,8]$. Trata-se aqui também de uma argumentação baseada nos "experimentos" ("experimento constat"). O primeiro indício que ele relata é a água que depois de esquentada, removendo-se o agente que a aqueceu, retorna a sua friúra anterior. Trata-se aqui da idéia de que a água tem uma tendência a ser mais fria que o ambiente circundante. Suárez pensa que o princípio que leva a água a se resfriar assim só pode ser a forma substancial pois o ar circundante naturalmente é tão frio como a água. A discussão deste indício é surpreendentemente complexa (também surpreendente para um livro de metafísica pois a discussão é basicamente física) e não podemos segui-la aqui. Mas podemos mencionar que a discussão dos indícios recorre ainda ao argumento da inseparabilidade dos acidentes como a correlação entre calor e rarefação $[15,1,13]$ e a subordinação das propriedades que sugerem a subsistência da forma substancial $[15,1,14]$.

O terceiro argumento de Suárez para demonstrar a forma substancial é a análise das suas causas, isto é, apenas da causa final, da eficiente e da material, pois a causa formal da forma substancial é ela mesma. Destas três causas Suárez considera como mais relevante a análise da causa final. A finalidade da forma substancial é completar a essência do ente natural; sem ela nada na natureza atingiria o seu grau de perfeição, pois a matéria apenas é um ente muito imperfeito ("valde imperfectum ens"). Além disso a matéria enquanto primum subjectum é uma e a mesma em todas as coisas, logo não pode consistir apenas nela a essência de todas as coisas naturais, pois se assim o fosse tudo não diferiria senão a partir dos acidentes 0 que repugna à beleza do universo à qual se deve a extrema variedade das espé- 
cies. Esta variedade é também evidenciada pelas mútuas gerações e atividades das coisas naturais tal como já se demonstrou.

E, por fim, Suárez alega que este ato que completa a essência da coisa material não pode ser somente um ato acidental. $<1>$ Primeiro porque de um ato e de uma potência de ordem diferentes não se pode chegar a que uma essência se complete de um modo uno. $<2>$ Depois porque como a matéria é uma potência substancial ele não pode ser desdobrado por um ato acidental. $<3>$ Em terceiro lugar, se se supusesse que este ato fosse acidental então se poderia perguntar do que ele seria um acidente. Do composto de matéria e forma não poderia a forma ser um acidente, pois isto seria o mesmo que dizer que a brancura é acidente do branco. $<4>$ Mas se este ato advém apenas à matéria há que se perguntar por que chamálo de acidente. $<4.1>$ Talvez porque se possa dizer que a matéria por vezes ocorre junto com este ato e por vezes não. Mas isto não é suficiente senão se poderia dizer também que a alma racional é um acidente do corpo (reparar aqui que esta demonstração da forma substancial recorre também à alma racional que é já - desde o primeiro argumento - tida como uma incontestável evidência de que há formas substanciais). $<4.2>$ Ou talvez poque tal forma dependeria da matéria para existir, pois em si seria uma entidade imperfeita e diminuta; mas isto também não é propriamente suficiente para que digamos que este ato é um acidente, pois partes substanciais podem depender de outras partes assim como, aliás, a própria matéria de certo modo depende da forma, ou seja, há vários modos de dependência que não são repugnantes para uma natureza incompleta. $<4.3>\mathrm{Ou}$ talvez ainda porque se diga que um acidente tem uma entidade de ordem inferior à substância como um todo. Mas dizer isto é gratuito e sem fundamento pois é absurdo dizer que o ato da forma ao qual a matéria está intrinsecamente ordenado seja inferior ou menor do que o ato da matéria. Sendo assim pode-se concluir que repugna à finalidade da forma dizer que ela não pode compor uma essência substancial que conste do sujeito substancial (matéria) e do ato da forma - alegando-se erroneamente que este seria meramente acidental - pois é exatamente a forma que dá o grau último e a completude da essência.

Trata-se aqui nesta demonstração da existência e da necessidade da forma substancial, tal como na demonstração da existência de uma matéria primeira, não de uma demonstração propter quid, mas de uma negotiatio da razão. Parte-se de observações ("experimento") e chega-se a conclusões que são por sua vez compatíveis com outras conclusões anteriores.

Nesta disputatio Suárez segue abordando outros temas tradicionais da discussão escolástica sobre as formas substanciais. Busca esclarecer a relação da forma com a matéria e como a forma enquanto causa formal exerce a sua causalidade, depois acaba por refutar a doutrina da pluralidade das formas. ${ }^{10}$ Suárez defende a unidade da forma substancial; aqui também a sua argumentação - como quase sempre - é minuciosa e exaustiva. É impossivel expô-la hoje aqui.

10 Foi na verdade no séc. XIII quando o debate sobre a pluralidade ou unidade da forma substancial, em particular no homem (teria o homem uma forma corpórea, uma alma animal e uma alma racional?), foi mais aguçado. 


\section{Considerações finais}

A discussão de Suárez a respeito da matéria primeira e da forma substancial é bem composta e bem conduzida, aborda quase todos os problemas que a tradição escolástica propunha sobre o tema. Não se trata porém das disputationes de maior destaque nas DM; nelas não há nenhuma posição de maior relevância. Suárez tende nelas a seguir Duns Scot o que também não é propriamente uma novidade. $O$ que nestas disputationes é mais sintomático para uma análise do pensamento de Suárez é o fato de ele tê-las incluído (elas e toda a série de disputações sobre as causas) nas DM. Aqui se evidencia o seu conceito de metafísica como amplo e caminhando contra a proposta esboçada por Benedito Pereira, a saber, a de separar a metaphysica generalis da metaphysica specialis. Nisto Suárez afasta-se da escola escotista que tende a excluir a física da metafísica.

O importante é notar que as suas discussões da matéria primeira e da forma substancial são não somente compatíveis como ainda estão em harmonia com todas as outras disputações. Não se pode dizer que nestas disputações haja propriamente qualquer ruptura da sistematicidade das DM. As rupturas estão, como indiquei, em outro lugar. Apenas as conseqüências das rupturas estão presentes, a saber, no recurso à teoria dos modos, teoria que está intimamente relacionada com a teoria das distinções, que por sua vez pressupõe a doutrina da denominatio extrinseca.

Um aspecto que não cheguei a abordar com ênfase aqui foi a questão do suppositum, a saber, a do relacionamento entre essência e suppositum, entre substantia secunda e substantia prima. Tal é o tema da disputação 34.

Mas por hoje tudo isto talvez tenha sido suficiente para indicar que a afirmação de que o aristotelismo seria uma forma de pensamento mais próxima do senso comum é problemática, pois a complexidade da substância vista como um composto físico ou vista como um composto metafísico (e aqui talvez a sutileza dos problemas seja ainda muito maior) parece ser muitas vezes maior do que o senso comum poderia imaginar. A complexidade da substância é em todo o caso bem maior na escolástica do que os estudantes de filosofia hoje, em sua maioria, chegam a se dar conta.

Visto isto gostaria de propor duas séries de questões para a discussão. A primeira série diz respeito ao relacionamento entre filosofia e teologia. A segunda série diz respeito ao significado, por assim dizer, epistemológico da recusa da doutrina das formas substanciais por Descartes.

Na discussão por Suárez das formas substanciais e da estrutura da substância em geral se pode observar repetidas interferências do discurso teológico no discurso filosófico. As principais interferências estão relacionadas com:

1) a transubstanciação

2) a imortalidade da alma e a possibilidade de sua existência separada do corpo

3) a encarnação de Jesus

4) a Trindade. 
Os itens 3 e 4 dizem respeito a considerações acerca da substantia prima. Não apresentei hoje o tema da substantia prima, mas basta dizer que se trata de interferências da mesma ordem que a transubstanciação.

$\mathrm{O}$ que quero destacar aqui é que o discurso teológico não necessariamente implica a fé.

Pode-se mesmo dizer que, baseando-se na exegese atual, é absurdo se supor que os primeiros cristãos e mesmo o próprio Jesus tinham fé na imortalidade da alma (eles acreditavam na ressurreição), que acreditavam que o suppositum do homem Jesus era divino e não humano e criado ou que o pão consagrado não era pão mas a substância do corpo de Jesus na qual ineririam os acidentes do pão. Crer nisto não deve portanto ser acriticamente tomado como sendo fé.

Além disso é um ato de fé se crer que há uma continuidade da fé, isto é, crer que os católicos hoje - ou da época pós-tridentina - têm a mesma fé que os cristãos seguidores de Jesus é já um ato de fé. Como poderia um filósofo afirmar tal continuidade?

Do mesmo modo - ainda que se aceite que há de fato algo como a fé e que ela tem sido a mesma - não há por que se pressupor que na Idade Média e "na sua extensão barroca" nos séc. XVI e XVII havia uma prática mais autêntica da fé do que, p. ex., atualmente, pois o que havia era um determinado tipo de discurso teológico com suas concomitantes práticas, ou melhor, uma determinada rede discursiva teológica. Antes temos como resultado da discussão exegética do séc. XIX, quando o cristianismo confrontou-se e assimilou a filologia moderna (e mesmo contribuiu para que ela se desenvolvesse) que exatamente a metafísica teria sido um desvio perdurando por séculos, soterrando em uma longa noite metafísica a mensagem originária do evangelho. Os séculos da metafísica teriam sido os séculos de maior opressão, de maior desentendimento da fé. Sob esta ótica se poderia mesmo dizer que a Idade Média e a escolástica foram como que o apogeu deste desentendimento. $\mathrm{O}$ discurso teológico escolástico seria assim o desentendimento da fé.

Assim se teria de recusar as interpretações da escolástica que vêem nela um conflito entre razão e fé. Nem a teologia implicaria assim tão simplesmente a fé, nem ela estaria em contraposição com a razão. Trata-se afinal de teologia. (Além disso há muitos temas mesmo da metafísica, mas também da física e da lógica e semântica que pouca relação têm com o discurso teológico.)

Notar também como o discurso teológico tanto pode ser um discurso que estimula a fé, como um que bloqueia a fé, como um que leva ao desespero. Pode também ser um discurso produtor de uma ilusão determinada. No tempo de Suárez as discussões teológicas acerca da predestinação levaram muitos ao desespero. Assim nos narra Lessius:

"Causa conscribendi huius Disputationis <sc. De praedestinatione et reprobatione > fuit, quod longo usu deprehenderim, multorum animos, praedestinationis consideratione valde perturbari. Scio quosdam inde in gravissimos melancholiae affectus incidisse: alium studium pietatis, et statum Religionis abiecisse: alios paene per totam vitam in anxietate versari, praedestinatinem Dei suspectam semper habentes. Tenuit etiam ea res me aliquot annis perplexum... Gravissima profecto est ista animi afflictio, et interdum tanta, ut homines ad desesperatinem et mortem spontaneam adigat." 
Falta que se empreenda uma análise do discurso teológico sem o pressuposto de que ele seja um "discurso da fé". A teologia escolástica é, na verdade, uma complexa rede discursiva, estimuladora e controladora de outros discursos. Foi já com os ditos Pais da Igreja e os concilios e talvez sobretudo com Agostinho que a teologia começou a assumir a posição de rede discursiva controladora e estimuladora de outros discursos sociais. Foi talvez só no séc. XIX que a rede discursiva científica veio em grande estilo assumir este papel: este foi o verdadeiro triunfo da ciência no séc. XIX.

É inclusive importante notar a interferência do discurso teológico no próprio "discurso da fé", quer dizer, no discurso de Paulo Apóstolo (a rigor não creio que se deva dizer que Paulo tinha uma teologia), a saber, quando, p. ex., Tomás de Aquino comenta a crucifixão de Jesus e dá várias explicações racionais e razoáveis para

isto que o próprio apóstolo Paulo disse ser $\mu \omega \rho \iota \alpha$. (cf. SthIII q. 46 a. 4 ou o comentário In epistolam I ad Corintios c. 1 lectio 3). Que a radicalidade do discurso paulino parece ficar em grande parte neutralizada não há dúvida; que a neutralização não chega a se mostrar total é porém também possível de se perceber. ( $\mathrm{E}$ como afinal abordar a questão de que a fé excede toda a neutralização da teologia? ${ }^{11}$ Em todo o caso não se pode deixar de constatar uma clara heterogeneidade entre estes dois discursos. (E quanto ao discurso teológico de Agostinho?)

Mas finalizemos esta conferência esboçando a segunda série de questões: as questões epistemológicas. Formularei estas questões aqui como que em contraponto às posições de Thomas Kuhn ou, ao menos, fazendo uso de alguns de seus conceitos. Quanto à teoria das formas substanciais e ao seu abandono ao longo do séc. XVII não se pode falar em crise, uma vez que a doutrina das formas substanciais sempre foi tida como problemática e sempre se buscou reformulá-la. Não se pode também falar em perda de evidência pois a evidência sempre foi parcial, isto é, a explicação da relação entre corpo e alma sempre exigiu engenhosas discussões e não se pode dizer que tais explicações tenham chegado a estar no domínio de um suposto senso comum; o que sustentava a doutrina das formas substanciais parece nem tanto ter sido um suposto caráter de evidência, mas antes a sua interrelação (inter-relação eivada de problemas não resolvidos) com outros discursos. Não se pode falar que se ergueu um novo - por assim dizer - paradigma pois as formas substanciais continuaram sendo consideradas e aceitas (ao menos na medicina e saberes correlatos). E, por fim, não se pode falar que o novo "paradigma" (o paradigma cartesiano) resolveu mais problemas ou problemas mais cruciais pois 0 novo paradigma não resolvia os problemas teológicos nem se mostrou produtivo para a discussão na medicina e saberes correlatos

Para finalizar quero deixar para o debate a questão da hegemonia do discurso da teologia na Idade Média e no início da Era moderna. Há que se questionar até

11 Tomás de Aquino por mais que ostentasse um certo tom bem caracteristico de clareza e simplicidade em suas explicações, inclusive nas explicações de mistérios divinos, sempre soube que tais mistérios são inalcançáveis para a razão humana. Há que se discutir melhor a retórica de Tomás de Aquino e analisar como ele lida com o que excederia os limites do racional (cf. In epist. I ad Corintios c. 1 lec. 3: "excessum humanae virtutis", "inquantum excedit sensum humanum", "quia superexcedit sapientiam humanam"). 
que ponto se dá uma tal hegemonia. Há que se pôr de lado o preconceito, sem dúvida ingênuo, de que se trata de um período que foi mais cristão que os subseqüentes. A hegemonia do discurso teológico deve ser discutida como sendo a hegemonia de um discurso. O que leva a que um discurso se imponha como hegemônico em uma época? Quais as estratégias específicas ao discurso hegemônico próprio à teologia escolástica? Qual a relação deste discurso hegemônico com a fé? (Há que se discutir também a própria questão do que seja ou não a fé.) Quais as relações do discurso teológico com os discursos científicos, bem como com os demais discursos de então?

\section{Referências bibliográficas}

ALCORTA, J. I. La teoria de los modos en Suárez. Madrid, 1949.

ELORDUY, Eleuterio. 'La acción de resultancia en Suárez', in: Anales de la Cátedra Francisco Suárez, n. 3 , fasc. 1-2, 1963, p. 45-71.

LESSIUS, Leonardus. De praedestinatione et reprobatione, in: id. Opuscula, Antuerpiae, 1626.

RIOS, André Rangel. Die Wahrheit der Aussagesätze und das göttliche Wissen von zukünftig Kontingentem bei Francisco Suárez. Berlin, Diss., 1991.

SCHIMITT, C. B., SKINNER, Q., KESSLER, E. (eds.). The Cambridge History of Renaissance Philosophy Cambridge, Cambridge Univ. Press, 1988.

SUÁREZ, Francisco. Opera omnia ed. c. Berton, Paris. 